\title{
RESEARCH
}

\section{Remote Work in Pharmacy Academia and Implications for the New-Normal}

\author{
William Allan Prescott Jr., PharmD, ${ }^{\mathrm{a}, \mathrm{b}}$ Daniel R. Kennedy, PhD, ${ }^{\mathrm{c}}$ Judith DeLuca, PharmD ${ }^{\mathrm{d}}$ \\ ${ }^{\text {a }}$ University at Buffalo, School of Pharmacy and Pharmaceutical Sciences, Buffalo, New York \\ ${ }^{\mathrm{b}}$ Editorial Board Member, American Journal of Pharmaceutical Education, Arlington, Virginia \\ ${ }^{c}$ Western New England University, College of Pharmacy and Health Sciences, Springfield, Massachusetts \\ ${ }^{\mathrm{d}}$ Wilkes University, Nesbitt School of Pharmacy, Wilkes-Barre, Pennsylvania
}

Corresponding Author: William Allan Prescott Jr., University at Buffalo, School of Pharmacy and Pharmaceutical Sciences, 218 Pharmacy Building, Buffalo, NY 14214. Tel: 716-645-4780. Email: prescott@ buffalo.edu

Submitted November 3, 2021; accepted February 1, 2022; ePublished February 2022

Objective. To determine the extent pharmacy faculty engaged in remote-work during the first two years of the COVID-19 pandemic, and secondarily to characterize pharmacy faculty and administrator perceptions of remote-work.

Methods. A 28-question online survey was sent to 6,548 American Association of Colleges of Pharmacy (AACP) members. Questions centered on the extent of remote-work and perceptions of its impact on productivity, effectiveness, and work-life balance. Focus groups were held to provide additional insight. Data were analyzed statistically, with a priori level of significance set at less than 0.05 .

Results. 6,322 AACP members met inclusion criteria, of whom 1,293 responded to the survey (21\% response-rate). At least one faculty and one administrator responded from 139 (99\% response-rate) and 126 schools (89\% response-rate), respectively. During the pandemic, $97 \%$ of faculty were permitted to work remotely, $94 \%$ of whom did so at least "some of the time". Most faculty indicated no change or an improvement in productivity (85\%) and effectiveness $(80 \%)$. Similarly, most administrators indicated no change or an increase in their unit's productivity $(81 \%)$ and effectiveness $(85 \%)$. More than one-half of respondents indicated better work-life balance while working remotely.

Conclusion. Nearly all respondents were permitted to work remotely at least "some of the time" during the pandemic. Considering most faculty and administrators believe productivity and effectiveness were not compromised, and that there appear to be benefits to work-life balance, US schools of pharmacy should consider permitting faculty to work remotely some of the time, as we navigate the pandemic and thereafter.

Keywords: pharmacy, remote-work, productivity, effectiveness, work-life balance

\section{INTRODUCTION}

The novel coronavirus 2019 (COVID-19) pandemic transformed the way we work and live. While incredibly tragic, the pandemic presents an opportunity to change the way we as faculty engage in the triad of academia. As Brazeau and colleagues mentioned, "it is vital that the academy learn from this situation and adapt so we can achieve our mission, vision, and goals."

It is estimated that just over half the US workforce holds a job that is compatible with remote work. ${ }^{2}$ Before the COVID-19 pandemic, data from Gallup indicated that $40 \%$ of employees worked at home at least some of the time, however, less than 5\% did so half-time or more. The pandemic changed this: In 2021, it was estimated that $70 \%$ of employees worked from home, ${ }^{2}$ with more than one-half of US employees expressing an interest in working remotely all or most of the time, and one-third indicating the desire to do so some of the time, after the pandemic abates. ${ }^{3}$ Global Workplace Analytics projects that following the pandemic, there will be a significant upswing in adoption of remote work among entities that had not yet ventured into this arena; this could include academia seeing as there are aspects of an academic's job that do not entirely need to be done on campus. ${ }^{2}$ As Brazeau and colleagues noted, "the COVID-19 pandemic has shaken the key assumptions and beliefs that serve as the foundation of higher education."1

The primary objective of this study was to determine the extent to which pharmacy faculty engaged in remote work during the 2019-20 and 2020-21 academic years (ie, during the first two years of the COVID-19 pandemic). The secondary objectives were to characterize faculty and faculty administrator (hereafter referred to as "administrators") perceptions of remote work in pharmacy academia, including its impact on productivity, effectiveness, and work-life balance, and to gauge administrator perspectives regarding its implications for the future. 


\section{METHODS}

A total of 6,548 faculty and professional staff from 141 US colleges and schools of pharmacy (hereafter referred to as "schools"), holding membership in the American Association of Colleges of Pharmacy (AACP), were identified through the AACP member database. Each school was assigned to one of four regions of the United States. ${ }^{4}$ Each school's status as a private or public institution was obtained from the Pharmacy College Application Service website. ${ }^{5}$ Faculty and administrators from schools located outside the US (including US territories) and those without faculty representation in AACP were excluded.

A 28-question survey instrument was developed and piloted at four schools of pharmacy: Four faculty members and four administrators assessed question clarity, overall flow, length of the survey instrument, and whether the survey adequately addressed the study's primary and secondary objectives. Responses from these individuals were reviewed and the survey instrument was revised. The study was deemed exempt by our university's institutional review board on May 25,2021 . The survey instrument inquired about demographics; whether the faculty member was permitted to work remotely during the COVID-19 pandemic (ie, during the 2019-20 and 2020-21 academic years, hereafter referred to as the "pandemic"), and if so, to what extent using a 5-point Likert scale ranging from "never" to "always"; faculty member perceptions regarding remote work and its impact on productivity and effectiveness using a 5-point Likert scale ranging from "significantly declined" to "significantly improved", and work-life balance using a 5-point Likert scale ranging from "significantly worse" to "significantly better"; administrator perceptions regarding the impact remote work had on their unit's productivity and effectiveness using the before-mentioned Likert scale; and administrator plans for remote work at their school in the future (ie, after the pandemic). Faculty and administrators were asked to answer questions on their own behalf. The survey was administered via SurveyMonkey (SurveyMonkey, Inc., Portland, OR) and skip logic was utilized to mitigate survey fatigue by directing the respondent down appropriate paths depending on their previous responses.

E-mail addresses for AACP members were obtained through purchase of the AACP full roster e-mail list. An electronic hyperlink to the survey instrument was e-mailed on May 27, 2021, and reminders were sent three and six weeks later to the same e-mail list. The survey remained open for a total of 10 weeks. The survey response rate and the distribution of responses were determined to generalize the findings.

Six focus groups were held to provide additional insight (four faculty groups and two administrator groups). Each focus group included a facilitator (the primary investigator), a scribe (a co-investigator), and 3-4 faculty or administrators. The facilitator and scribe took notes independently and compared their notes following each session. Each investigator independently identified themed categories and came to a consensus to identify coinciding themes. Faculty were asked what they liked best/least about remote work and if/how they remained productive and maintained work-life balance while working remotely. Administrators were asked what they liked best/least about remote work, strategies they used to encourage productivity and work-life balance among faculty in their unit, and how they envision the "new-normal" in terms of remote-work once the pandemic abates.

Data were analyzed using Microsoft Excel, GraphPad (GraphPad Software, San Diego, CA), and https://astatsa.com/. Frequency and descriptive statistics were used to characterize the data. Overall productivity and effectiveness were determined by calculating the mean Likert score for each respondent based on their ratings in didactic teaching, experiential teaching, research, clinical practice, college/school service, professional service, and administration. The Chi-square and Fisher's exact tests were used to analyze categorical data, the paired t-test and Wilcoxon Signed-Rank tests were used to analyze paired data, the unpaired t-test and ANOVA were used to analyze unpaired continuous data, and the Wilcoxon Rank Sum and Kruskal-Wallis tests were used to analyze ordinal data. The a priori level of significance was less than 0.05 .

\section{RESULTS}

Of the 6,548 AACP members, 226 were excluded: 29 did not meet inclusion criteria and 197 were not reachable via e-mail. From the remaining 6,322 AACP members, a total of 1,293 responses were received (21\%-member response rate). Demographics are provided in Table 1. At least one faculty and administrator response were received from 139/141 (99\% response rate) and 126/141 (89\% response rate) schools, respectively. The mean and median number of faculty responses per school were $9.3+5.1$ and 9 (IQR 6-12), respectively (range 1-32). The mean and median number of administrator responses per school were $2.7 \pm 1.5$ and 2 (IQR 2-4), respectively (range 1-7).

Prior to the pandemic, less than $20 \%$ of faculty worked remotely at least "some of the time". Approximately $85 \%$ of respondents indicated at least a moderate portion of their job can be done remotely: This ranged from $81 \%$ for faculty having a primary focus of clinical practice ( $p<.005 \mathrm{vs}$. foci in teaching, research, and service/administration) to $94 \%$ for service/administration ( $p<.0001$ vs. foci in teaching and clinical practice). During the pandemic, $97 \%$ of faculty were permitted to work remotely, $94 \%$ of whom did so at least "some of the time" and $66 \%$ of whom did so "most of the time" or "always". Whether or not a faculty member was permitted to work remotely during the pandemic, and the extent to 
which they did, was not affected by the type of their position (ie, faculty vs. administration), track, or rank. Faculty in social/administrative sciences were more likely to work remotely than faculty in other academic areas $(p<.005)$, while faculty in medicinal/pharmaceutical chemistry were less likely to do so $(p<.05)$. Faculty whose primary role was clinical practice were less likely to work remotely than faculty whose primary role was either teaching, research, or service/administration $(p<.05)$. Responses to survey questions about remote work by respondent demographics are summarized in Table 2 . More than $80 \%$ of respondents indicated a desire to work remotely at least some of the time after the pandemic abates.

Faculty perceptions about productivity and effectiveness are shown in Table 3. More than one-half of respondents indicated experiencing no change in overall productivity (62\%) or effectiveness (59\%) while working remotely during the pandemic, and an increase was noted by $23 \%$ and $21 \%$ of respondents, respectively. Although more than one-half of respondents indicated either no change or an improvement in their productivity and effectiveness in each academic pillar (Table 3), more than one-third perceived declines in clinical practice productivity (35\%), didactic teaching effectiveness (44\%), and both productivity and effectiveness in experiential teaching (36\% and $42 \%)$ and research (41\% and $37 \%)$. Faculty who worked remotely "at least some of the time" perceived that they were more productive $(p<.0001)$ and effective $(p<.005)$ than those who "never" or "rarely" did so. Similarly, faculty who worked remotely "most of the time" or "always" perceived that they were more productive $(p<.0001)$ and effective $(p<.0001)$ than those who reported working remotely less frequently, with significant differences noted in the areas of didactic teaching, research, college/school service, professional service, and administration. Perceived overall productivity (median Likert score $=3$ in both groups, $p=.86$ ) and effectiveness (median Likert score $=3.0$ in both groups, $p=0.86$ ) among pharmacy practice faculty who ranked clinical practice as their primary focus $(\mathrm{n}=169)$ was like that of faculty in any department whose primary duty was other than clinical practice. In contrast, faculty who ranked research as their primary focus $(\mathrm{n}=188)$ perceived their overall productivity (median Likert score $=3.0$ in both groups, $p<.05$ ) and effectiveness (median Likert score $=2.8$ vs. $3.0, p<.005$ ) to be slightly lower than that of faculty in any department whose primary duty was other than research. Female faculty reported slightly higher overall productivity (median Likert score 3.0 vs. $2.9, p<.005$ ) and effectiveness (median Likert score 2.9 vs. 2.8, $p<.05$ ) than their male counterparts. Our study included 620 respondents $(48 \%)$ with a dependent under the age of 18 years in the home: Overall productivity and effectiveness did not vary between faculty with and without dependents.

A total of 337 administrators from 126 schools responded. Sixty-three percent of administrators indicated no change in their unit's overall productivity while faculty worked remotely during the pandemic, while $19 \%$ perceived a decrease and $18 \%$ perceived an increase in productivity. Similarly, $61 \%$ of administrators indicated no change in their unit's overall effectiveness, while $25 \%$ perceived a decrease and $14 \%$ perceived an increase in effectiveness. Of concern, more than one-third of respondents indicated their unit experienced a decline in didactic teaching effectiveness (47\%), and a decline in both productivity and effectiveness in experiential teaching (38\% and 47\%), research (47\% and 46\%), and clinical practice (41\% and $41 \%$ ). Nearly $90 \%$ of administrators believed faculty should be permitted to work remotely at least some of the time after the pandemic abates.

Faculty perceptions regarding the impact remote work had on work-life balance are shown in Table 4. As compared to before the pandemic, a lower percentage of respondents indicated being moderately, very, or extremely satisfied with their job while working remotely $(76.1 \%$ vs. $90.6 \%)(p<.0001)$. However, $75 \%$ and $57 \%$ of respondents indicated having better flexibility in their workday and better work-life balance while working remotely, respectively. Faculty who worked remotely "at least some of the time" during the pandemic perceived that they had better work-life balance than those who never/rarely did so $(p<.0001)$. When asked to rate their productivity, level of personal interaction with colleagues, and level of emotional exhaustion before the pandemic, more than $95 \%$ of respondents indicated having at least moderate levels of productivity and personal interaction with colleagues, while $27 \%$ expressed high levels of emotional exhaustion. During the pandemic, the percentage of respondents reporting at least moderate levels of productivity decreased to $86 \%$, the percentage of respondents reporting at least moderate levels of personal interaction with colleagues decreased to $36 \%$, and the percentage of respondents reporting high levels of emotional exhaustion nearly doubled to $51 \%$ (all $p<.0001$ ). As compared to faculty who worked remotely less frequently, productivity and personal interaction were higher, and emotional exhaustion lower, among faculty who worked remotely "most" or "all the time" $(p<.05)$. Pharmacy practice faculty who ranked clinical practice as their primary focus reported similar work-life balance (median Likert score $=4.0$ in both groups, $p=.54$ ) and similar levels of emotional exhaustion (median Likert score $=4.0$ in both groups, $p=.08$ ) during the pandemic, as compared to faculty in any department whose primary duty was other than clinical practice. Better work-life balance was noted for female faculty, those without an administrative role, and those with at least one dependent under the age of 18 years (Table 4).

Six focus groups were held during August 2021: This included two groups of three administrators and four groups of four faculty. The participants were evenly distributed by sex (10 female, 10 male), institution type (10 R1, 10 non-R1), 
track ( 9 nontenure, 11 tenured/tenure-track faculty), and rank (6 assistant professors, 10 associate professors, and 4 professors). Themes from the focus groups were consistent with the quantitative findings and offer additional insight as to what faculty and administrators liked best/least about remote work (Table 5). Faculty generally perceived they were productive in the remote work environment. Strategies used by faculty to optimize productivity included realigning the workday to accommodate home responsibilities and thereby minimize distractions, and staying focused through structure (eg, establishing routine working hours, setting goals, prioritizing tasks, creating checklists, and setting deadlines).

Faculty generally felt they were able to maintain work-life balance while working remotely. Strategies used by faculty to achieve balance included living in the moment (ie, avoiding e-mail when not working), re-evaluating household processes to share workload, setting reasonable boundaries between work and home, being flexible with deadlines, blocking time to work on important projects, and embracing the advantages of working from home (eg, casual dress, working outside, completing chores during natural work breaks). Strategies administrators used to encourage productivity and work-life balance among faculty in their unit included focusing on the high priority issues, optimizing the role of support staff to protect faculty time, revising performance expectations, promoting flexible work schedules, modeling appropriate work hours, scheduling regular meetings and check-ins with colleagues, creating time for informal conversations amongst colleagues, advocating exercise, and encouraging faculty to take breaks and use vacation time. When administrators were asked how they envision the "new-normal" in terms of remote-work once the pandemic abates, they noted the advantages of hybrid meetings (if attendees are engaged in group discussions), flexible work schedules, remote work, and virtual learning to complement in-person didactic and experiential teaching.

\section{DISCUSSION}

The primary objective of this study was to determine the extent to which pharmacy faculty engaged in remote work during the pandemic. Unsurprisingly, the percent of responding faculty who worked remotely at least "some of the time" increased from less than $20 \%$ before the pandemic to $94 \%$ during the pandemic. The extent to which a faculty member worked remotely varied by discipline, with medicinal/pharmaceutical chemists working remotely less often than social/administrative scientists, likely due to differences in the portability of their research and scholarship. Similarly, the amount that a faculty member worked from home varied by the nature of their position, with faculty having a clinical practice focus being least likely to work remotely, likely owing to the need to be on-site for patient care and experiential education duties.

The pandemic prompted schools of pharmacy to change the way they do business. Romanelli and colleagues equated these changes to crossing the Rubicon, suggesting it will be nearly impossible to go back to the old way of doing things. ${ }^{6}$ Our data support this perspective: Four in five pharmacy faculty members and administrators expressed a desire to continue working remotely at least some of the time after the pandemic abates, which aligns with national data outside academia. ${ }^{2,7}$ In support, nearly $90 \%$ of administrators believe faculty should be permitted to do so. Why might this be the case? First, most respondents perceived no change or an increase in their effectiveness or productivity while working remotely. Second, most respondents appreciated the flexibility in their workday. Third, respondents who worked remotely at least some of the time perceived benefits to work life balance.

Productivity and effectiveness should be at the forefront of decisions that affect workplace dynamics. Four in five respondents perceived either no change or an increase in their effectiveness and productivity while working remotely. In line with this, $80 \%$ and $75 \%$ of administrators perceived either no change or an increase in their unit's productivity and effectiveness, respectfully. This aligns with data across the US: A fall 2020 survey conducted by Flex Jobs indicated $95 \%$ of respondents felt their productivity was higher or the same while working remotely. ${ }^{8}$ That said, it must be noted approximately one-third of administrators perceived that their unit experienced a decline in didactic teaching effectiveness, and a decline in both productivity and effectiveness in experiential teaching, research, and clinical practice. Considering this, a hybrid approach which permits or encourages some aspects of academic work to be done remotely while expecting other aspects (eg, teaching and laboratory/bench-top research) to be done mostly in-person, seems justified.

A previous study, conducted in 2012, indicated $64 \%$ of pharmacy faculty were satisfied with their job and $37 \%$ were satisfied with their work-life balance. ${ }^{9}$ In our study, $76 \%$ of faculty remained satisfied with their job, and most faculty also realized improved work-life balance and flexibility while working remotely. This is increasingly important to workers and can impact recruitment and retention. Data from the Flex Jobs 2020 Annual Survey indicated nearly threequarters of employees view work-life balance as a primary factor when seeking employment, while $80 \%$ indicate that loyalty to their employer was related to flexible work schedules. ${ }^{7}$ All that said, $24 \%$ and $28 \%$ of faculty reported worsening job satisfaction and work-life balance during the pandemic, respectively. This is likely multifactorial, but feedback collected through the focus groups suggest difficulty balancing work and family responsibilities, and reduced 
interaction with colleagues and students, to be noteworthy, the latter of which appears to be more related to remote-work than the former.

The risk of burnout, which is the culmination of three factors, emotional exhaustion, depersonalization, and decreased personal accomplishment, ${ }^{9-11}$ was heightened during the pandemic. In a 2014 study of US pharmacy practice faculty, $41 \%$ and $11 \%$ of respondents reported high levels of emotional exhaustion and depersonalization, respectively, while $24 \%$ of respondents reported low levels of personal accomplishment. Our study, which extended beyond pharmacy practice faculty, slightly differed, with $27 \%$ and $5 \%$ of respondents reporting high levels of emotional exhaustion and depersonalization, respectively, while $2 \%$ of respondents reported low levels of personal accomplishment. Pharmacy Practice faculty with clinical practice responsibilities may have been at heightened risk for burnout during the pandemic, the degree to which was likely influenced by how their school and practice site managed faculty engagement in patient care duties. For example, some sites may have dismissed faculty (and students) to lessen physical presence in their facilities, others may have expected faculty to shift patient care duties to telehealth, while others may have maintained "business as usual." Given the differing impact each approach could have on burnout risk, it is not surprising that our data did not reveal higher degrees of perceived burnout among pharmacy practice faculty having a primary role of clinical practice. Darbishire and colleagues published a commentary in 2020, in which they stated, "the academy must proactively

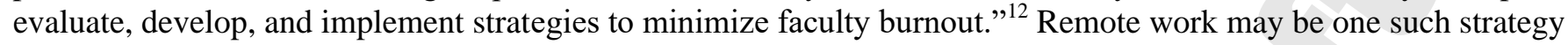
because respondents who worked remotely "most" or "all the time" indicated having higher levels of productivity and personal interaction, and lower levels of emotional exhaustion, as compared to those who more frequently worked on-site.

Adoption of remote work among industries that have not yet ventured into this arena is expected. ${ }^{2}$ Our study indicates there is a desire among pharmacy faculty and administrators to follow suit. The question that remains to be answered is, should academia pivot to remote work, and if so, to what extent? Academia may desire to hold on to its brick-and-mortar roots, which run deep; however, change is inevitable. Considering that a strong majority of respondents felt that working remotely did not negatively affect their productivity and effectiveness, and may have improved it, permitting faculty to work remotely, to some extent, should not compromise the ability of institutions to meet their mission. Furthermore, the benefits of remote work on flexibility and work-life balance may improve recruitment and retention of talented faculty, while also positively impacting individual and organizational productivity and effectiveness. ${ }^{13}$ We would be remiss to ignore the flip side of the coin, that one-third of faculty reported their effectiveness and/or productivity was compromised in clinical practice, research, and most notably teaching. Evidence-based approaches to remote learning in pharmacy academia (and other health professions) are needed, but pending that, maintaining in-person instruction for the majority of the PharmD curriculum seems wise. A singular model may not work for all, and administrators should work with their faculty to determine what academic duties are best done in-person and what can be done remotely.

There are several limitations of this study. Although the response rate for US schools and colleges of pharmacy was $99 \%$, the faculty response rate was only $21 \%$. A response rate less than $60 \%$ increases the risk of nonresponse bias, making it difficult to generalize findings to all US pharmacy faculty. However, as the respondents represented nearly all pharmacy schools for faculty and roughly $90 \%$ for administrators, we believe we have a representative sample of the academy. Another limitation is the survey was only sent to faculty listed on the AACP roster, potentially contributing to bias as members of AACP may have a higher level of enthusiasm for academia compared to non-members. Traditional qualitative methods such as recording and transcribing focus group sessions were not utilized, which introduces subjectivity and limits the validity of the focus groups. Furthermore, neither productivity nor effectiveness were explicitly defined, and the data collected through both the survey and focus groups centered on perceptions. Therefore, it is plausible that our results differ from actual productivity and effectiveness, though if that were the case, we would have expected a difference between faculty and administrator responses. Lastly, impact of the pandemic versus working remotely on productivity, effectiveness, and work-life balance cannot be distinguished since the two factors occurred simultaneously.

\section{CONCLUSION}

Nearly all responding faculty were permitted to work remotely during the COVID-19 pandemic, approximately 95\% of whom did so at least "some of the time". Most faculty and administrators perceived there was no change in their own or their unit's overall productivity or effectiveness while working remotely and permitting faculty to work remotely appears to have encouraged better work-life balance. Considering nearly all faculty feel at least a moderate portion of their job can be done remotely, that productivity and effectiveness do not appear to be compromised, and that there appear to be benefits to work-life balance, US schools of pharmacy should consider permitting faculty to work remotely at least some of the time, as we continue to navigate the pandemic and thereafter.

\section{ACKNOLWEDGEMENTS}


We would like to thank Dr. Jennifer Lamberts for her assistance with survey instrument design. We would also like to thank Drs. Diptiman Bose, Nicholas Fusco, Heather Girand, Michelle Sahr, Erin Slazak, Joshua Spooner, Scott Stolte, and Kim Ference for pilot testing the survey instrument.

\section{REFERENCES}

1. Brazeau GA, Frenzel JE, Prescott WA. Facilitating wellbeing in a turbulent time. Am J Pharm Educ 2020; 84(6): Article 8154.

2. Global Workplace Analytics. https://globalworkplaceanalytics.com/work-at-home-after-covid-19-our-forecast. Accessed April 17, 2021.

3. Pew Research Center: How the Coronavirus Outbreak Has - and Hasn't - Changed the Way Americans Work. https://www.pewresearch.org/social-trends/2020/12/09/how-the-coronavirus-outbreak-has-and-hasnt-changed-theway-americans-work. Accessed April 17, 2021.

4. Census Regions and Divisions of the United States. https://www2.census.gov/geo/pdfs/mapsdata/maps/reference/us_regdiv.pdf. Accessed April 17, 2021.

5. Pharmacy College Application Service (PharmCAS). Compare Programs: Public or Private. https://www.pharmcas.org/school-directory/explore-and-compare/public-or-private. Accessed April 17, 2021.

6. Romanelli F, Rhoney DH, Black EP, Conway J, Kennedy DR. Pharmacy Education Crosses the Rubicon. Am J Pharm Educ 2020;84(6): Article 8131.

7. Flex Jobs. FlexJobs Survey: Why Flexible Work Should Matter to Employers. https://www.flexjobs.com/employerblog/flexjobs-survey-flexible-work-employers/. Accessed October 22, 2021.

8. Flex Jobs. FlexJobs Survey: Productivity, Work-Life Balance Improves During Pandemic. https://www.flexjobs.com/blog/post/survey-productivity-balance-improve-during-pandemic-remote-work/. Accessed October 22, 2021.

9. Lindfelt TA, Ip EJ, Barnett MJ. Survey of career satisfaction, lifestyle, and stress levels among pharmacy school faculty. Am J Health-Syst Pharm 2015;72(18):1573-8.

10. Maslach C. Burnout: The Cost of Caring. Cambridge, MA: Malor Books; 2003.

11. El-Ibiary SY, Yam L, Lee KC. Assessment of Burnout and Associated Risk Factors Among Pharmacy Practice Faculty in the United States. Am J Pharm Educ 2017;81(4): Article 75.

12. Darbishire P, Isaacs AN, Miller ML. Faculty Burnout in Pharmacy Education. Am J Pharm Educ 2020;84(7): Article7925.

13. Kennedy DR, Clapp P, DeLuca JL, et al. Enhancing Pharmacy Faculty Well-Being and Productivity while Reducing Burnout. Am J Pharm Educ 2021: Article 8764. Available @ https://www.ajpe.org/content/early/2021/08/21/ajpe8764.

Table 1. Demographics of Faculty from US PharmD Programs Participating in a Remote Work Survey

\begin{tabular}{lc}
\hline & $\begin{array}{c}\text { Respondents } \\
\text { No. }(\%)\end{array}$ \\
Demographic & N=1293 \\
\hline Geographic Region of Faculty Member's Program & $370(28.6)$ \\
Midwest & $229(17.7)$ \\
Northeast & $491(38.0)$ \\
South & $203(15.7)$ \\
West & \\
Type of Institution where Faculty Member is Employed & $717(55.5)$ \\
Private & $576(44.5)$ \\
Public & \\
Type of Position & $940(72.7)$ \\
Faculty & $337(44.2)$ \\
Faculty Administrator ${ }^{\text {a }}$ & $11(0.9)$ \\
NR & $710(54.9)$ \\
Track & $572(44.2)$ \\
Non-Tenure & $11(0.9)$ \\
Tenure-Track/Tenured &
\end{tabular}


Assistant Professor

$365(28.2)$

Associate Professor

$476(36.8)$

Professor

$401(31.0)$

Distinguished Professor

$14(1.1)$

Other $^{\text {b }}$

$28(2.2)$

NR

$9(0.7)$

Academic Area

Medicinal/Pharmaceutical Chemistry

$82(6.3)$

Pharmaceutics

$71(5.5)$

Pharmacology/Biological Sciences

$150(11.6)$

Pharmacy Practice

$844(65.3)$

Social/Administrative Sciences

$137(10.6)$

NR

$9(0.7)$

FTE

1.0

$1231(95.2)$

0.5 to $<1.0$

$44(3.4)$

$10(0.8)$

$8(0.6)$

Sex

Female

$710(54.9)$

Male

$471(36.4)$

Prefer not to answer / NR

$112(8.7)$

Race/Ethnicity

Asian

$113(8.7)$

Black

$49(3.8)$

$33(2.6)$

Hispanic/Latino

$947(73.2)$

White or Caucasian

$17(1.3)$

Prefer not to answer / NR

$134(10.4)$

Marital Status

Married or Domestic partnership

$963(74.5)$

Single

$206(15.9)$

124 (9.6)

Prefer not to answer / NR

$88(6.8)$

$246(19.0)$

$310(24.0)$

$226(17.5)$

$268(20.7)$

$59(4.6)$

$175(13.5)$ NR

$\mathrm{NR}=$ Not reported; FTE $=$ Full time equivalent; ${ }^{\mathrm{a}}$ Associate/Assistant Dean $(\mathrm{n}=129)$, Department Chair $(\mathrm{n}=81)$,

Division Head $(n=61)$, Department Vice-Chair $(n=42)$, Dean $(n=24) ;{ }^{b}$ Instructor/Lecturer $(n=18)$, Endowed Professor $(\mathrm{n}=4)$, Academic Professional $(\mathrm{n}=4)$, Director / Assistant Director/Coordinator Experiential Education $(\mathrm{n}=1)$,

Department Chair $(\mathrm{n}=1)$

Table 2. Remote Work Among Pharmacy Faculty During the COVID-19 Pandemic

\begin{tabular}{|c|c|c|c|}
\hline Demographic & $\begin{array}{c}\text { Remote Work } \\
\text { Permitted } \\
\text { No. }(\%) \\
\end{array}$ & $\begin{array}{c}\text { Extent of Remote } \\
\text { Work }^{\text {a }} \\
\text { Mean } \pm \text { SD }\end{array}$ & $\begin{array}{c}\text { Extent of Remote } \\
\text { Work }^{\mathrm{a}} \\
\text { Median (IQR) }\end{array}$ \\
\hline All Respondents $(\mathrm{n}=1293)$ & $1250(96.7)$ & $3.8 \pm 0.90$ & $4.0(3-5)$ \\
\hline \multicolumn{4}{|l|}{ Type of position $(n=1234)$} \\
\hline Faculty & $325(96.4)$ & $3.8 \pm 0.9$ & $4.0(3-5)$ \\
\hline Faculty administrator & 909 (96.7) & $3.8 \pm 0.9$ & $4.0(3-4)$ \\
\hline \multicolumn{4}{|l|}{ Track $(n=1240)$} \\
\hline Non-Tenure & $685(96.5)$ & $3.9 \pm 0.9$ & $4.0(3-5)$ \\
\hline
\end{tabular}


Tenure-Track/Tenured

Academic Rank ( $n=1208)$

Assistant Professor

Associate Professor

Professor / Distinguished Professor

Academic Area $(n=1242)$

Medicinal/Pharmaceutical Chemistry

Pharmaceutics

Pharmacology/Biological Sciences

Pharmacy Practice

Social/Administrative Sciences

Primary Role $(n=1239)$

Clinical Practice

Research

Service/Administration

Teaching

\begin{tabular}{ccc}
$555(97.0)$ & $3.8 \pm 0.9$ & $4.0(3-4)$ \\
$348(95.6)$ & $3.9 \pm 0.9$ & $4.0(3-5)$ \\
$461(97.5)$ & $3.8 \pm 0.8$ & $4.0(3-4)$ \\
$399(96.8)$ & $3.8 \pm 0.8$ & $4.0(3-4)$ \\
& & \\
$80(97.6)$ & $3.6 \pm 0.9^{\mathrm{b}}$ & $4.0(3-4){ }^{\mathrm{c}}$ \\
$68(95.8)$ & $3.9 \pm 0.8$ & $4.0(3-4.25)$ \\
$144(96.0)$ & $3.8 \pm 0.9$ & $4.0(3-4)$ \\
$818(96.9)$ & $3.8 \pm 0.9$ & $4.0(3-4)$ \\
$132(96.4)$ & $4.3 \pm 0.9{ }^{\mathrm{d}}$ & $4.0(4-5)$ \\
& & \\
$183(97.3)$ & $3.7 \pm 0.9^{\mathrm{e}}$ & $4.0(3-4)$ \\
$190(96.4)$ & $4.0 \pm 0.9$ & $4.0(3-5)$ \\
$247(96.9)$ & $3.9 \pm 0.9$ & $4.0(3-5)$ \\
$619(96.7)$ & $3.8 \pm 0.9$ & $4.0(3-4)$ \\
\hline${ }^{\mathrm{b}} \mathrm{p}<.05$ vs. pharmaceutics, pharmacy practice, and \\
\end{tabular}

social/administrative sciences; ${ }^{\mathrm{c}} \mathrm{p}<.05$ vs. all academic areas; ${ }^{\mathrm{d}} \mathrm{p}<.005$ vs. all academic areas; ${ }^{\mathrm{e}} \mathrm{p}<.05$ vs. all other roles.

Table 3. Perceived Productivity and Effectiveness Among Pharmacy Faculty Who Reported Working Remotely During the COVID-19 Pandemic

\begin{tabular}{|c|c|c|c|c|c|c|}
\hline \multirow[b]{2}{*}{ Demographic } & \multirow{2}{*}{$\begin{array}{c}\text { No } \\
\text { perceived } \\
\text { change, } \\
\text { No. }(\%)\end{array}$} & \multirow[t]{2}{*}{$\begin{array}{c}\text { Perceived } \\
\text { improvement, } \\
\text { No. }(\%)\end{array}$} & \multicolumn{2}{|c|}{$\begin{array}{l}\text { Faculty who worked } \\
\text { remotely at least some } \\
\text { of the time }\end{array}$} & \multicolumn{2}{|c|}{$\begin{array}{c}\text { Faculty who } \\
\text { never/rarely worked } \\
\text { remotely }^{\text {a }}\end{array}$} \\
\hline & & & $\underset{\text { SD }}{\operatorname{Mean} \pm}$ & $\begin{array}{c}\text { Median } \\
\text { (IQR) }\end{array}$ & $\underset{\text { SD }}{\operatorname{Mean}} \pm$ & $\begin{array}{c}\text { Median } \\
\text { (IQR) }\end{array}$ \\
\hline Overall productivity $(\mathrm{n}=1241)^{b}$ & & & $3.1 \pm 0.7^{\mathrm{c}}$ & $3.0(3-3)^{c}$ & $2.8 \pm 0.6$ & $2.8(2-3)$ \\
\hline Teaching, didactic $(n=1218)$ & $591(48.5)$ & $383(31.4)$ & $3.2 \pm 0.9^{\mathrm{c}}$ & $3.0(3-4)^{c}$ & $2.7 \pm 0.8$ & $3.0(2-3)$ \\
\hline Teaching, experiential $(n=817)$ & $372(45.5)$ & $150(18.4)$ & $2.8 \pm 1.0$ & $3.0(2-3)$ & $2.7 \pm 0.6$ & $3.0(2-3)$ \\
\hline Research $(n=1190)$ & $338(28.4)$ & $364(30.6)$ & $2.9 \pm 1.2^{\mathrm{d}}$ & $3.0(2-4)^{d}$ & $2.5 \pm 1.0$ & $3.0(2-3)$ \\
\hline Service, college $(n=1230)$ & $623(50.7)$ & $383(31.1)$ & $3.2 \pm 0.9^{\mathrm{d}}$ & $3.0(3-4)^{f}$ & $2.9 \pm 0.8$ & $3.0(2-3)$ \\
\hline Service, profession $(n=1200)$ & $596(49.7)$ & $355(29.6)$ & $3.2 \pm 1.0^{\mathrm{e}}$ & $3.0(3-4)^{\mathrm{e}}$ & $2.8 \pm 0.9$ & $3.0(2-3)$ \\
\hline Administration $(\mathrm{n}=832)$ & $455(54.7)$ & $269(32.3)$ & $3.3 \pm 0.9^{\mathrm{e}}$ & $3.0(3-4)^{\mathrm{e}}$ & $2.9 \pm 0.7$ & $3.0(3-3)$ \\
\hline Clinical practice $(n=647)$ & $322(49.8)$ & $100(15.5)$ & $2.8 \pm 0.9$ & $3.0(2-3)$ & $2.8 \pm 0.7$ & $3.0(2-3)$ \\
\hline Overall effectiveness $(n=1238)^{b}$ & & & $3.0 \pm 0.7^{\mathrm{e}}$ & $3.0(3-3)^{\mathrm{e}}$ & $2.8+0.5$ & $2.8(2-3)$ \\
\hline Teaching, didactic $(n=1218)$ & $378(31.0)$ & $309(25.4)$ & $2.8 \pm 1.0^{\mathrm{d}}$ & $3.0(2-4)^{\mathrm{d}}$ & $2.6 \pm 0.9$ & $2.0(2-3)$ \\
\hline Teaching, experiential $(n=814)$ & $342(42.0)$ & $134(16.5)$ & $2.7 \pm 1.0$ & $3.0(2-3)$ & $2.6 \pm 0.7$ & $3.0(2-3)$ \\
\hline Research $(n=1186)$ & $406(34.2)$ & $340(28.7)$ & $2.9 \pm 1.2^{\mathrm{d}}$ & $3.0(2-4)^{d}$ & $2.6 \pm 1.0$ & $3.0(2-3)$ \\
\hline Service, college $(n=1224)$ & $645(52.7)$ & $359(29.3)$ & $3.2 \pm 0.9^{\mathrm{e}}$ & $3.0(3-4)^{d}$ & $3.0 \pm 0.7$ & $3.0(3-3)$ \\
\hline Service, profession $(n=1192)$ & $638(53.5)$ & $314(26.3)$ & $3.1 \pm 0.9^{\mathrm{f}}$ & $3.0(3-4)^{\mathrm{e}}$ & $2.8 \pm 0.8$ & $3.0(2-3)$ \\
\hline Administration $(\mathrm{n}=832)$ & $454(54.6)$ & $235(28.2)$ & $3.2 \pm 0.9^{\mathrm{e}}$ & $3.0(3-4)^{\mathrm{e}}$ & $2.8 \pm 0.8$ & $3.0(2.3-3)$ \\
\hline Clinical practice $(n=653)$ & $337(51.6)$ & $110(16.8)$ & $2.8+0.9$ & $3.0(2-3)$ & $3.0 \pm 0.7$ & $3.0(3-3)$ \\
\hline
\end{tabular}

${ }^{\mathrm{a}}$ 5-point Likert scale: Significantly declined to significantly improved; ${ }^{\mathrm{b}}$ Calculated based on respondent means for each category; ${ }^{\mathrm{c}}$ $\mathrm{p}<.0001 ;{ }^{\mathrm{d}} \mathrm{p}<.05 ;{ }^{\mathrm{e}} \mathrm{p}<.005 ;{ }^{\mathrm{f}}<.01$.

Table 4. Work-life Balance Among Pharmacy Faculty Who Reported Working Remotely During the COVID-19 Pandemic

\begin{tabular}{lcc} 
Demographic & Mean + SD & Median $($ IQR) \\
\hline Type of Position & & \\
Faculty (n=906) & $3.5 \pm 1.3$ & $4.0(2-5)^{\mathrm{b}}$ \\
Faculty Administrator $(\mathrm{n}=325)$ & $3.4 \pm 1.2$ & $4.0(2-4)$ \\
Sex & $3.6 \pm 1.3^{\mathrm{c}}$ & $4.0(2-5)^{\mathrm{c}}$ \\
$\quad$ Female $(\mathrm{n}=686)$ & $3.3 \pm 1.2$ & $4.0(2-4)$ \\
$\quad$ Male $(\mathrm{n}=451)$ & &
\end{tabular}


Married or Domestic partnership ( $\mathrm{n}=931)$

Single $(\mathrm{n}=197)$

Respondents with $\geq 1$ dependent $(\mathrm{n}=774)$

Respondents with $\geq 1$ dependent $<18$ years $(\mathrm{n}=600)^{\text {d }}$

$$
\begin{array}{ll}
3.5 \pm 1.3 & 4.0(2-5) \\
3.3 \pm 1.3 & 4.0(2-4) \\
3.5 \pm 1.3 & 4.0(2-5) \\
3.5 \pm 1.3 & 4.0(2-5) \\
3.8 \pm 1.2 & 4.0(3-5) \\
3.7 \pm 1.3 & 4.0(2-5) \\
3.5 \pm 1.4 & 4.0(2-5) \\
3.4 \pm 1.2 & 4.0(2-4)
\end{array}
$$

Infants aged $<1$ year $(\mathrm{n}=87)$

Children aged $1-5$ years $(n=236)$

Children aged 6-12 years $(\mathrm{n}=302)$

Adolescents aged $13-17$ years $(n=216)$

Frequency at which faculty worked remotely

$\begin{array}{lll}\text { At least some of the time } & 3.5 \pm 1.3^{\mathrm{e}} \quad 4.0(2-5)^{\mathrm{e}}\end{array}$

Never/rarely

\begin{tabular}{|c|c|c|}
\hline Topic & Domain & Themes \\
\hline \multirow[t]{4}{*}{$\begin{array}{l}\text { What faculty liked best about } \\
\text { remote work / Perceived } \\
\text { advantages }\end{array}$} & General & $\begin{array}{l}\text { Improved flexibility in where/when work; reduced } \\
\text { commute time; improved time management; ease of } \\
\text { collaborating with colleagues }\end{array}$ \\
\hline & Communication & $\begin{array}{l}\text { Ease of virtual connectivity with colleagues and } \\
\text { students }\end{array}$ \\
\hline & Research/Scholarship & Dedicated time for scholarly activities \\
\hline & Education & Integration of technology to teach online \\
\hline \multirow[t]{4}{*}{$\begin{array}{l}\text { What faculty liked least about } \\
\text { remote work / Perceived } \\
\text { challenges }\end{array}$} & General & $\begin{array}{l}\text { Difficult balancing family responsibilities; lack of / } \\
\text { inadequate remote workspace (eg, home office, } \\
\text { unreliable internet); "Zoom fatigue"; distractions / } \\
\text { interruptions }\end{array}$ \\
\hline & Communication & $\begin{array}{l}\text { Less interaction / sense of community with colleagues } \\
\text { and students; fewer spontaneous interactions }\end{array}$ \\
\hline & Research/Scholarship & Delays in publication process \\
\hline & Education & $\begin{array}{l}\text { Difficulty engaging students through online learning; } \\
\text { increased workload (eg, converting in-person classes } \\
\text { online); reduced academic performance among students } \\
\text { engaged in online learning; impersonal virtual } \\
\text { classroom setting; difficulty in assessing student } \\
\text { learning; concerns about student mental health }\end{array}$ \\
\hline \multirow{2}{*}{$\begin{array}{l}\text { What administrators liked best } \\
\text { about remote work }\end{array}$} & General & Reduced commute time; improved time management \\
\hline & Communication & $\begin{array}{l}\text { Improved faculty/staff attendance at virtual meetings } \\
\text { (eg, off-site faculty, at distance campuses) }\end{array}$ \\
\hline \multirow[t]{2}{*}{$\begin{array}{l}\text { What administrators liked } \\
\text { least about remote work }\end{array}$} & General & $\begin{array}{l}\text { Distractions at home; Increased workload due to } \\
\text { pandemic-related challenges }\end{array}$ \\
\hline & Communication & $\begin{array}{l}\text { Less interaction among colleagues; difficult } \\
\text { maintaining a sense of community within unit }\end{array}$ \\
\hline
\end{tabular}

$2.7 \pm 1.3 \quad 3.0(2-3)$

${ }^{\mathrm{a}}$ 5-point Likert scale: Significantly declined to significantly improved;

${ }^{\mathrm{b}} \mathrm{p}<.05$ vs. faculty administrator;

${ }^{\mathrm{c}} \mathrm{p}<.0005$ vs. male;

${ }_{\mathrm{d}}^{\mathrm{p}}<.05$ vs. faculty with no dependent children/adolescents;

${ }^{\mathrm{e}} \mathrm{p}<.0001$ vs. never/rarely

Table 5. Thematic Comments from Faculty and Administrators Focus Groups on Remote-Work 